\title{
Análisis de los canales de comercialización del brócoli en Ecuador
}

\section{Analysis of the marketing channels of broccoli in Ecuador}

\author{
Pedro Iván Vélez Duque ${ }^{1 \text { https://orcid.org/0000-0001-5886-4387, }}$ \\ Antonio Álava Murillo 1 https://orcid.org/0000-0002-9786-7879 \\ ${ }^{1}$ Universidad Agraria del Ecuador, Guayaquil, Ecuador \\ pvelez@uagraria.edu.ec, aalava@uagraria.edu.ec
}

\section{Resumen}

El cultivo del brócoli es un producto que dinamiza la economía del país generando empleo, principalmente, en las provincias productoras de esta hortaliza como: Cotopaxi, Chimborazo, Tungurahua, Imbabura y Pichincha. En estos lugares, en los últimos años, se ha venido incrementando las superficies de siembra, debido al aumento de la demanda en los mercados nacionales e internacionales. ¿Cómo analizar los canales de comercialización de brócoli en Ecuador? El presente trabajo de investigación tiene como objetivo analizar los canales de comercialización de brócoli en Ecuador, mediante el uso de fuentes bibliográfícas. La investigación fue de tipo documental ya que se emplean libros, revistas científicas e informes sobre la producción y comercialización del brócoli en Ecuador, se utiliza los métodos inductivo, deductivo y analítico. Existe una creciente demanda de esta hortaliza en los mercados nacionales e internacionales, los principales destinos son los mercados de la Unión Europea, Estados Unidos, Japón, Canadá. Entre los híbridos y variedades que predominan están Avenger, Domador, Legacy y Marathon, debido principalmente a las condiciones de adaptabilidad a los factores climáticos y a su nivel de producción. Los competidores más fuertes para el país son: La Unión Europea, China, México. Los canales de comercialización de esta hortaliza están conformados por los pequeños y medianos productores, los intermediarios son las empresas procesadoras que son quienes exportan el producto hacia los diferentes destinos.

Palabras clave: hortaliza, mercado, precio, producto, producción.

Sumario: Introducción, Materiales y Métodos, Resultados y Discusión y Conclusiones.

Como citar: Álava, A. \& Vélez, P. (2021). Análisis de los canales de comercialización del brócoli en Ecuador. Revista Tecnológica - Espol, 33(3), 181-201.

http://www.rte.espol.edu.ec/index.php/tecnologica/article/view/857 


\begin{abstract}
Broccoli is a product that boosts the country's economy and generates employment, mainly in the broccoli-producing provinces of Cotopaxi, Chimborazo, Tungurahua, Imbabura, and Pichincha, which have been increasing their planting areas in recent years due to increased demand in domestic and international markets. The objective of this research is to analyze the broccoli marketing channels in Ecuador using bibliographic sources. The research was of a documentary type, using books, scientific journals, and reports on the production and commercialization of broccoli in Ecuador. Inductive, deductive, and analytical methods were used. There is a growing demand for this vegetable in national and international markets; the main destinations are the markets of the European Union, United States, Japan, and Canada. Among the hybrids and varieties that predominate are Avenger, Domador, Legacy, and Marathon, mainly due to their adaptability to climatic factors and their production level. The strongest competitors for the country are the European Union, China, and Mexico. The marketing channels for this vegetable are made up of small and medium-sized producers, and the intermediaries are the processing companies that export the product to different destinations.
\end{abstract}

Keywords: vegetable, market, price, product, production.

\title{
Introducción
}

El brócoli es una hortaliza localizada en el Mediterráneo y Asia Menor. En Italia, Libia y Siria, los principales ejemplares de esta planta se cosecharon a partir de coles y coliflores. El brócoli se desarrolla en ambientes suaves y suelos ricos en materia natural. Desde el punto de vista de la salud, aporta muchos minerales, proteínas y nutrientes (Cesaveg, 2001).

En los últimos años, el grado de comercialización del brócoli en el mercado mundial ha seguido aumentando. Comparado con otros productos de exportación no tradicionales, el brócoli es uno de los productos agrícolas con mayor demanda. Los principales destinos de esta hortaliza son Japón, Estados Unidos y la Unión Europea, y la demanda va en aumento. El motivo se debe, principalmente, a la evolución de los estilos de vida de las personas. Las personas prefieren comer comidas ligeras y variadas con menor tiempo de preparación. En los últimos años, la dieta es rica en nutrientes, que es beneficioso para la salud y previene enfermedades (Álvarez \& Álvarez, 2009).

Las variedades que mayormente se cultivan en el país son: Domador, Legacy y Marathon. El brócoli ecuatoriano es de muy buena calidad. A lo largo del tiempo, se ha diversificado la línea de artículos a través de mezclas y diferentes presentaciones; manteniendo primordialmente la calidad superior del brócoli que se posiciona en nichos de mercado altos donde justamente esta calidad supera al precio como factor concluyente de la compra (Organización de las Naciones Unidas para la Alimentación y la Agricultura [FAO], 2013).

En Ecuador, además logra un incremento paulatino, gracias a los cambios de hábitos alimenticios de la gente hacia un más grande consumo de hortalizas en su dieta día tras día. Las hortalizas proponen una opción muy clara para los agricultores medianos y chicos por su extensa variedad en sus productos, lo cual facilita una más grande seguridad en la venta utilizando el mercado en forma paralela (Giron \& Plazas, 2019).

En los años anteriores se le da una mejor consideración a su consumo, gracias a resultados de indagaciones que aseguran su eficacia en la prevención y control del cáncer. Siendo un producto muy perecedero debe ser almacenado con buena circulación de aire y espacio entre las canastillas para evadir el calentamiento (Luna, 2017). 
Esta hortaliza se constituye en uno de los comestibles que trae más provecho para el organismo es un vegetal que no debe faltar en la dieta de la familia por su gran contribución en vitaminas y minerales.

El cultivo de brócoli es un rubro que mueve el área agrícola, por el incremento del espacio establecido cada año, lo que crea fuentes de trabajo principalmente en los territorios de: Cotopaxi, Chimborazo, Tungurahua, que suma un importante rubro la economía nacional.

La actividad tiene una gran importancia económica para el país por lo siguiente:

1. El asentamiento del mayor conglomerado poblacional y, por consiguiente, su mayor fuente de trabajo.

2. El sustento real para la alimentación de la población.

3. La materia prima indispensable para la agroindustria, otra importante fuente de trabajo.

4. Un gran impulso para el sector comercial interno, por la oferta de productos primarios e industriales terminados.

5. Una inagotable fuente de divisas para el erario nacional, a través de la exportación de su producción (Larrea, 2016).

La publicidad de esta hortaliza es realizada por organizaciones comprometidas con el manejo y la comercialización del equivalente, quienes compran a pequeños y medianos productores a veces a bajos costos que regularmente no se hacen cargo de los costos de creación. Por ello, este trabajo de investigación pretende complementar los desvíos publicitarios y su importancia en la comercialización del brócoli en Ecuador, utilizando fuentes bibliográficas.

\section{Materiales y Métodos}

La presente investigación fue de tipo documental ya que se utilizaron libros, revistas científicas e informe sobre la producción y comercialización del brócoli en el Ecuador.

\section{Métodos de investigación Inductivo}

Este método permitió conocer los hechos del proceso de comercialización de esta hortaliza en Ecuador, a través de la búsqueda de la información para el establecimiento de conclusiones.

\section{Deductivo}

Este método se utilizó en el razonamiento de las diversas informaciones sobres la producción y comercialización del brócoli, para deducir conclusiones que parten de hechos particulares aceptados como válidos, en el presente estudio.

\section{Analítico}

Este método permitió analizar los componentes de la problemática del entorno a la comercialización de esta hortaliza para identificar falencias de la cadena de valor.

\section{Tipos de investigación Descriptiva}

Permitió describir la situación actual de los sistemas de producción de esta hortaliza, además identificar las costumbres alimenticias de la población, y comercialización. 


\section{Bibliográfica}

Sirvió como punto de partida para la realización del proceso investigativo, considerando para ello las fuentes de consultas bibliográficas o secundarias.

\section{Procedimiento metodológico} actividades:

Para realizar este trabajo de investigación documental se desarrollaron las siguientes

1. Una exhaustiva investigación sobre la producción, comercialización y consumo de brócoli y su aporte a la economía del país.

2. Sistematización de información secundaria para conocer el estado de la temática a partir de la lectura y evaluación de bibliografía de consulta y referencia de bases de datos de bibliotecas virtuales.

3. Accediendo a fuentes de información fidedignas para la selección del material a utilizar en el proceso de investigación, revisión del material para clasificarlos según orden de importancia del tema, organización de material para la obtención de las citas. El análisis de datos permitió elaborar el documento con la interpretación de la problemática de estudio, elaboración de conclusiones en función al objetivo de la investigación.

\section{Resultados y Discusión}

La presente investigación se encuentra respaldada en un análisis de campo y documental, luego de efectuarse la recolección de información secundaria, mediante la aplicación del análisis crítico de los datos estadísticos sobre la producción y comercialización del brócoli en Ecuador.

\section{El cultivo de brócoli}

Debido a la creciente demanda de esta hortaliza en los mercados nacionales e internacionales, ha ocasionado que otras provincias empiecen a producir sumándose a las tradicionales como: Cotopaxi, Chimborazo, Tungurahua, Imbabura y Pichincha, lo cual hace que aumente la superficie sembrada en el país. La expansión del cultivo del brócoli en esta región debe entenderse, a su vez, a la luz de la consolidación de un nuevo régimen agroalimentario en el ámbito mundial que impulsa un cambio en las dietas de los países del hemisferio norte, configurando de esta manera mercados nicho para la exportación, que comienza a ser abastecidos por las economías del sur (Rubio, 2016).

Los destinos más importantes del brócoli ecuatoriano son los mercados de la Unión Europea, Estados Unidos y Japón. En Ecuador existen 4 plantas procesadoras con una capacidad industrial instalada para producir y exportar unas 70000 toneladas métricas de brócoli congelado IQF anualmente. Esto significa una cosecha anual de aproximadamente 100 mil toneladas de brócoli fresco (Lìderes, 2017).

Esta hortaliza tiene muchos beneficios para la salud, por su gran valor nutricional y su aporte de minerales, vitaminas $\mathrm{C}$ y E, además de ácido fólico, en tanto que tiene muchas formas de poder combinarlo en la dieta como ensaladas, cremas, sopas, etc. El brócoli tiene un alto valor nutritivo y medicinal, que radica en su alto contenido de vitaminas, minerales, fibra, carbohidratos, dado su elevado valor nutricional, ha sido estudiado últimamente para prevención del cáncer (Mercola, 2017).

El brócoli cuyo nombre científico es (Brassica oleracea L. var. Itálica), pertenece a la familia de las crucíferas, es una típica hortaliza de climas templados que se adapta bien en 
algunas regiones semidesérticas, Mediterráneo oriental, Europa, Latino América, regiones asiáticas y Estados Unidos. La parte comestible de esta hortaliza es una inflorescencia inmadura (Zamora, 2016).

\section{Taxonomía del brócoli}

\begin{tabular}{ll}
\hline Reino: & Plantae \\
\hline División: & Magnoliophyta \\
Clase: & Magnoliopsida \\
Orden: & Brassicales \\
Familia: & Brassicaceae \\
Género: & Brassica \\
Especie: & Brassica oleracea L. \\
Nombre científico: & Brassica oleracea L. var. Itálica (García, 2016). \\
\hline
\end{tabular}

\section{Propiedades nutricionales del Brócoli}

El valor nutricional de los alimentos se basa en la cuantificación de las macromoléculas, el brócoli contiene vitaminas A, C, K y fibra. Su consumo frecuente es recomendado ya que puede reducir los riesgos de diabetes y anemia por su contenido de Hierro, así como algunos tipos de cánceres como colon, mama y próstata debido a algunos compuestos químicos anticancerígenos presentes en el alimento, conocidos como glucosinolatos (Zamora, 2016).

\section{Tabla 1}

Valor nutricional del brócoli

\begin{tabular}{lcc}
\hline \multicolumn{1}{c}{ Componentes } & $\begin{array}{c}\text { Brócoli crudo } \\
\text { Contenido Unidad }\end{array}$ & $\begin{array}{c}\text { Brócoli cocido } \\
\text { Contenido Unidad }\end{array}$ \\
\hline Agua & $91 \%$ & $90 \%$ \\
Carbohidratos & $5.3 \mathrm{~g}$ & $5.56 \mathrm{~g}$ \\
Proteínas & $2.65 \mathrm{~g}$ & $2.78 \mathrm{~g}$ \\
Lípidos & $0.66 \mathrm{~g}$ & $0.56 \mathrm{~g}$ \\
Calcio & $47.68 \mathrm{mg}$ & $113.8 \mathrm{mg}$ \\
Fósforo & $66.23 \mathrm{mg}$ & $47.68 \mathrm{mg}$ \\
Fierro & $0.86 \mathrm{mg}$ & $1.17 \mathrm{mg}$ \\
Potasio & $325.17 \mathrm{mg}$ & $162.78 \mathrm{mg}$ \\
Sodio & $27.15 \mathrm{mg}$ & $11.11 \mathrm{mg}$ \\
Vitamin a A(valor) & $1543.05 \mathrm{UI}$ & $1411.11 \mathrm{UI}$ \\
Tiamina & $0.07 \mathrm{mg}$ & $0.08 \mathrm{mg}$ \\
Riboflavina & $0.12 \mathrm{mg}$ & $0.21 \mathrm{mg}$ \\
Niacina & $0.66 \mathrm{mg}$ & $0.78 \mathrm{mg}$ \\
Ácido Ascórbico & $93.38 \mathrm{mg}$ & $62.78 \mathrm{mg}$ \\
Valor Energético & $26.49 \mathrm{cal}$ & $27.78 \mathrm{cal}$ \\
\hline Nota Descripción del valor nutricional datos tomado de Zamora, (2016). &
\end{tabular}

Nota. Descripción del valor nutricional datos tomado de Zamora, (2016).

\section{Variedades}

Entre los híbridos y variedades que predominan están Avenger, Domador, Legacy y Marathon, debido principalmente a las condiciones de adaptabilidad a los factores climáticos y a su nivel de producción. Las variedades existentes de brócoli son híbridos, lo que implica 
que se desarrollan genéticamente en laboratorios y que las plantas no producen semillas. En general estas variedades se clasifican, según su ciclo (entre 50 y 150 días) en tempranas, medias y tardías. Las diferencias radican en el color, tamaño de la planta y de la inflorescencia, en el grado de desarrollo de los brotes laterales, en su adaptabilidad a diversos climas y suelos, y en sus características genéticas (Luna, 2017).

Las variedades Legacy y Marathon son las que actualmente dominan la producción en todas las zonas, sobre todo la variedad Legacy que ha tenido un buen desarrollo en las regiones productoras de brócoli del Ecuador; y la razón principal es que se adapta con excelentes resultados a zonas altas. Se caracteriza por tener una pella bien formada que permite cortes de tallos relativamente cortos, con florets (cabezas) de consistencia firme, de grano pequeño (lo que la hace más compacta), forma adecuada y un color verde - grisáceo (Portilla, 2013).

Esta investigación incluye un análisis de los factores que determinan que el brócoli sea un producto competitivo en el ámbito industrial y comercial. Esto tendrá fuente informativa ya que otorga información acerca del producto y las ventajas que lo hacen competitivo en varios mercados (Flores, 2019).

El área de brócoli ayuda básicamente a las redes nativas de Cotopaxi y más de 3.300 familias son utilizadas en este movimiento. Los commodities son un importante manantial de comercio para el país. En 2018, Ecuador obtuvo 119 millones de dólares por la exportación de este insumo. (Orozco, 2019).

En Cotopaxi se dedican alrededor de 2.500 hectáreas al desarrollo del brócoli, que tarda entre 12 y 14 semanas en crearse, permitiendo su desarrollo tres veces al año, por lo que se desarrollan entre 6.000 y 7.000 hectáreas de este rubro cada año en la zona (Gómez, 2016).

El concepto actual según Patricio Gutiérrez, representante de Pro Ecuador en el tema de Brócoli, es la búsqueda de nuevos mercados dijo que, con la no renovación de las preferencias arancelarias con Estados Unidos, la capacidad del comprador para importar producto ecuatoriano queda reducida en comparación con los competidores más cercanos. Sin embargo, se ha redoblado esfuerzos para diversificar los mercados de destino del brócoli ecuatoriano (ProEcuador, 2014).

El brócoli es un producto no tradicional con un fuerte potencial para la exportación, debido al incremento en la demanda mundial. La producción del brócoli, entre el año 2000 al 2012, registra un crecimiento del 41.88\%, pasando de 14'989 000 toneladas producidas en el año 2000 a 21'266 789 toneladas en el 2012; presentando así, una tendencia positiva en este periodo de tiempo, con una tasa de crecimiento anual promedio de 2,99\% (Rendón, 2013).

\section{Análisis de los canales de comercialización del brócoli en Ecuador}

Para el desarrollo de este acápite se parte de la recolección y reorganización de los indicadores cuantitativos referentes a las dimensiones más relevantes de los canales de comercialización de los productos agropecuarios generados en Ecuador al respecto, fuentes secundarias.

\section{La demanda}

Desde el punto de vista del marketing como la estimación razonada de las posibilidades cuantitativas de ventas de un producto o de un servicio para un período determinado y para una clientela definida (Rivera y De Garcillán, 2012). 
Es bajo estas circunstancias como se satisfacen las necesidades de los consumidores frente a la oferta de los vendedores. La demanda tiene, adicionalmente, modalidades que ayudan a ubicar al oferente de bienes y servicios, en función de las necesidades de los demandantes. En primer lugar, hay bienes y servicios necesarios y bienes y servicios superfluos, de lujo o no necesarios. Para el caso de los bienes necesarios se trata de productos o servicios indispensables para el cliente, con los cuales satisface sus necesidades más importantes. En algunos casos, en función de los estratos sociales, algunos bienes o servicios se vuelven indispensables, pero no es igual para todos los niveles de consumo (Rojas, 2015).

El interés por el brócoli cultivado en el extranjero ha dado grandes resultados en el sector productivo en los últimos cinco años. Así lo ha descubierto Rafael Gómez de la Torre, dirigente de la Asociación de Productores de Frutas y Hortalizas (Aprofel). En los últimos cinco años, la creación se ha desarrollado un $10 \%$.

Los principales destinos de exportación son la Unión Europea con el 35\%, EE.UU. y Canadá con un porcentaje similar y el 30\% a Japón. Existen colocaciones marginales que van hacia el Oriente Medio. En la venta de brócoli al mundo, Ecuador tiene ventajas frente a sus competidores. Una de las más importantes es que produce todo el año gracias al clima, la salud de las plantas y el acceso al riego.

La competencia más fuerte está en México y Guatemala. El primero, según Aprofel, solo produce en ciertos períodos del año debido al clima y por una veda de producción para combatir una plaga. El segundo país, en cambio, no accede a riego todo el tiempo (Enriquez, 2017).

\section{Demanda de precios a nivel internacional del brócoli}

El brócoli es uno los productos de agroexportación de gran importancia económica para el país, el cual es muy apetecido en los mercados internacionales por su calidad, que representan alrededor de USD 83 millones de ingreso. El primer semestre se caracterizó por tener valores casi constantes, a excepción del mes de febrero donde se reportó un valor de USD 9.87/cartón 20 libras, siendo el valor más bajo del año. Para el segundo semestre, los precios se mantuvieron estables; sin embargo, durante los últimos meses del año se evidenció tendencia al alza en el precio, lo que provocó que para el último mes del año se reporte el valor de (USD 26.37/cartón 20 libras) (Ministerio de Agricultura y Ganaderia[MAG], 2018).

\section{Figura 1}

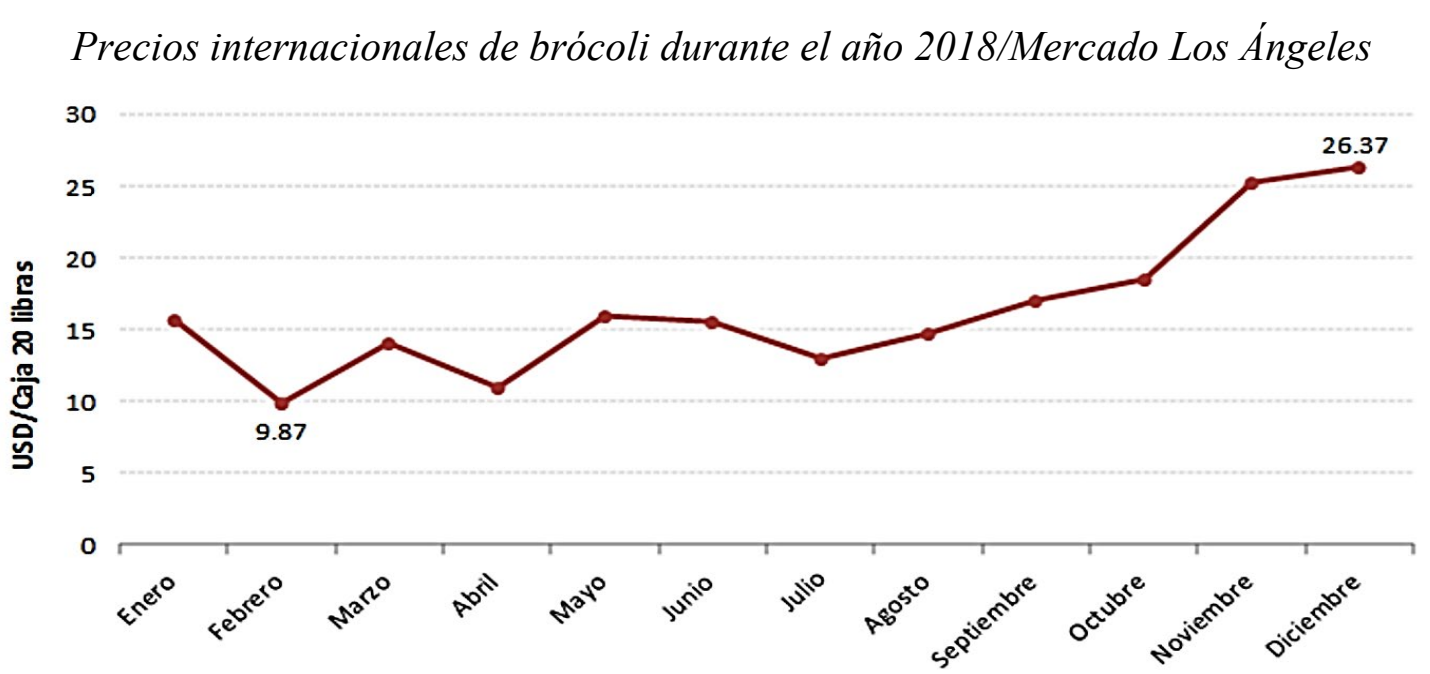

Nota. En la figura se muestran los precios en los mercados de Los Ángeles (MAG, 2018). 


\section{Demanda de precios a nivel nacional del brócoli}

El consumo de esta hortaliza ha aumentado paulatinamente en los últimos años, debido principalmente al cambio en los hábitos alimenticio de los hogares ecuatorianos, sin embargo, los precios en los mercados de transferencia se han mantenido. Los precios ponderados nacionales cotizados a nivel de productor de brócoli se mantuvieron sin variación; mientras que, los precios mayoristas (precio promedio de los mercados de Quito, Guayaquil y Cuenca) disminuyeron $11 \%$ en relación al año 2017, mostrando un comportamiento contrario a los precios internacionales (MAG, 2018).

\section{Figura 2}

Comparación de precios nacionales a nivel de productor y mercado mayorista

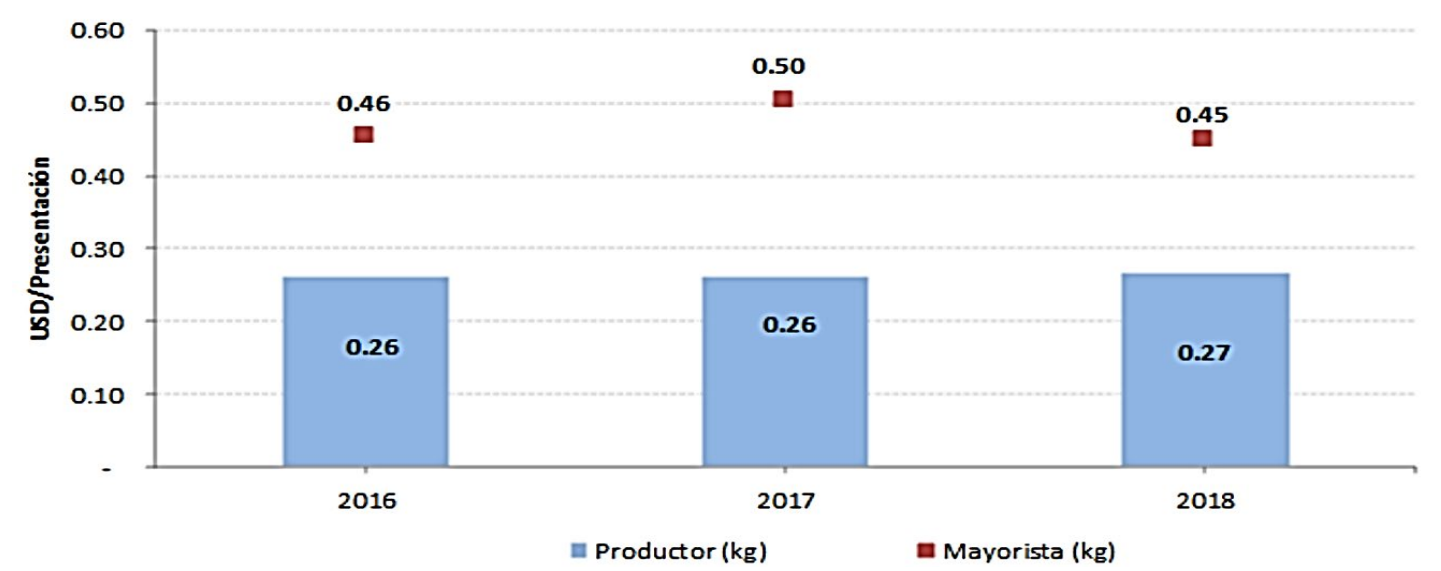

Nota. Precios promedio de los mercados de Quito, Guayaquil y Cuenca, para brócoli durante los años 2016, 2017 y 2018 MAG-SIPA.

\section{Importaciones a nivel internacional}

Los mercados internacionales han ido creciendo para esta hortaliza tan apetecida por sus bondades nutritivas, entre los principales países importadores están Estados Unidos, Reino Unido, Japón, Alemania, Francia, Bélgica, Corea del Sur, Canadá, Italia y Países Bajos. Las importaciones de brócoli a nivel mundial se han incrementado en un $2 \%$ con respecto al año 2017. Asimismo, para el año 2018, se registró el mayor volumen de importaciones que fue de 1'119 396 toneladas (MAG, 2018).

\section{Figura 3}

Importaciones mundiales de brócoli desde el año 2008 al 2018

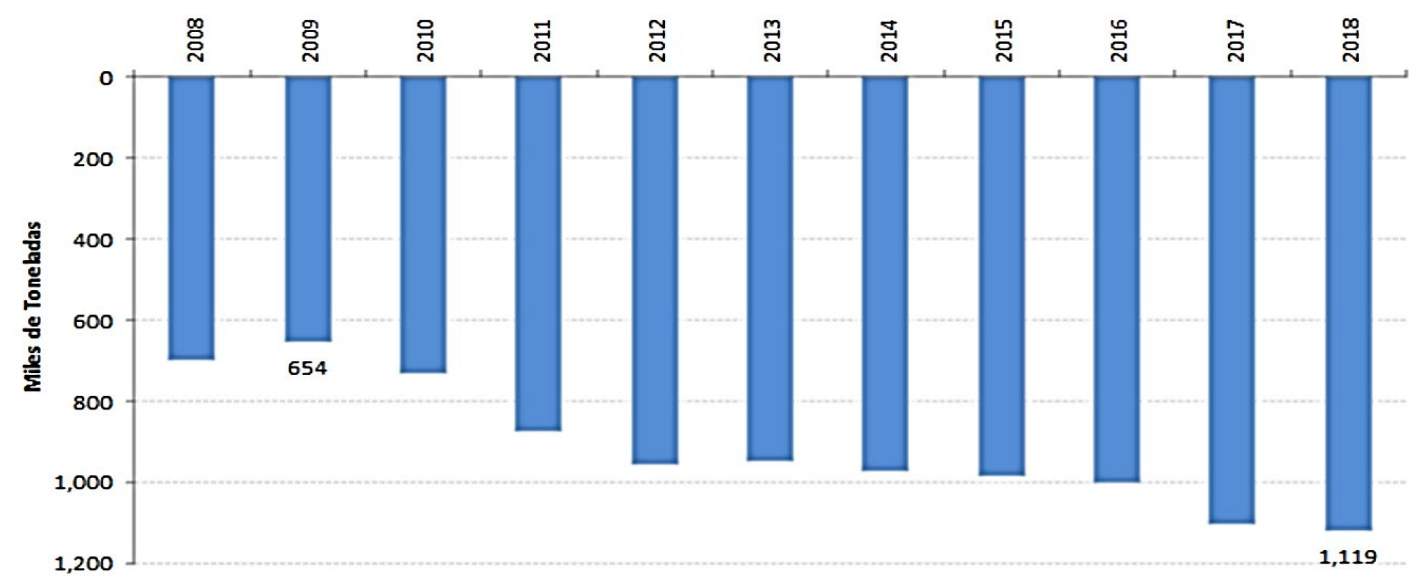

Nota. Análisis de las importaciones del brócoli, TRADEMAP (2019). 


\section{La oferta}

La oferta de brócoli en el país, está establecida por las empresas exportadoras que son quienes adquieren la hortaliza a los pequeños y medianos productores para procesarla de acuerdo a su capacidad instalada. Según Rojas (2015) sostiene que la oferta se define como la cantidad de bienes o servicios que se ponen a la disposición del público consumidor en determinadas cantidades, precio, tiempo y lugar para que, en función de éstos, aquél los adquiera. Así, se habla de una oferta individual, una de mercado o una total, (Economia, 2011) afirma que "En el análisis de mercado, lo que interesa es saber cuál es la oferta existente del bien o servicio que se desea introducir al circuito comercial" (pág. 1).

El pronóstico de la oferta consiste en tratar de identificar con la ayuda de distintas hipótesis, la probable evolución futura de la oferta. Para ello se requiere conocer: La probable utilización de la capacidad ociosa que presenta cada uno de los actuales proveedores.

Los planes y proyectos de ampliación de la capacidad instalada. Un análisis detallado de los factores que determinan la evolución futura de la oferta. Entre estos están la evolución estructural y coyuntural del sistema económico; los cambios probables del mercado proveedor; las medidas económicas que tengan un impacto sobre la producción, los precios, los tipos de cambio y las divisas; algunos factores aleatorios y naturales. El pronóstico de la oferta, basado en los factores antes descritos (Rojas, 2015).

\section{Producción a nivel internacional del brócoli}

La producción mundial del brócoli se ha incrementado en un promedio anual de un $2 \%$, entre los países productores de esta hortaliza constan China, india, Estados Unidos, México, España, Italia, entre otros. La producción mundial incrementó en $4 \%$ respecto al año 2016. La tendencia al alza se evidencia a lo largo del periodo analizado 2007-2017, registrando en el año 2017, el volumen más alto de producción 25’984 760 toneladas (MAG, 2018).

\section{Figura 4}

\section{Producción mundial de brócoli desde el año 2007 al 2017}

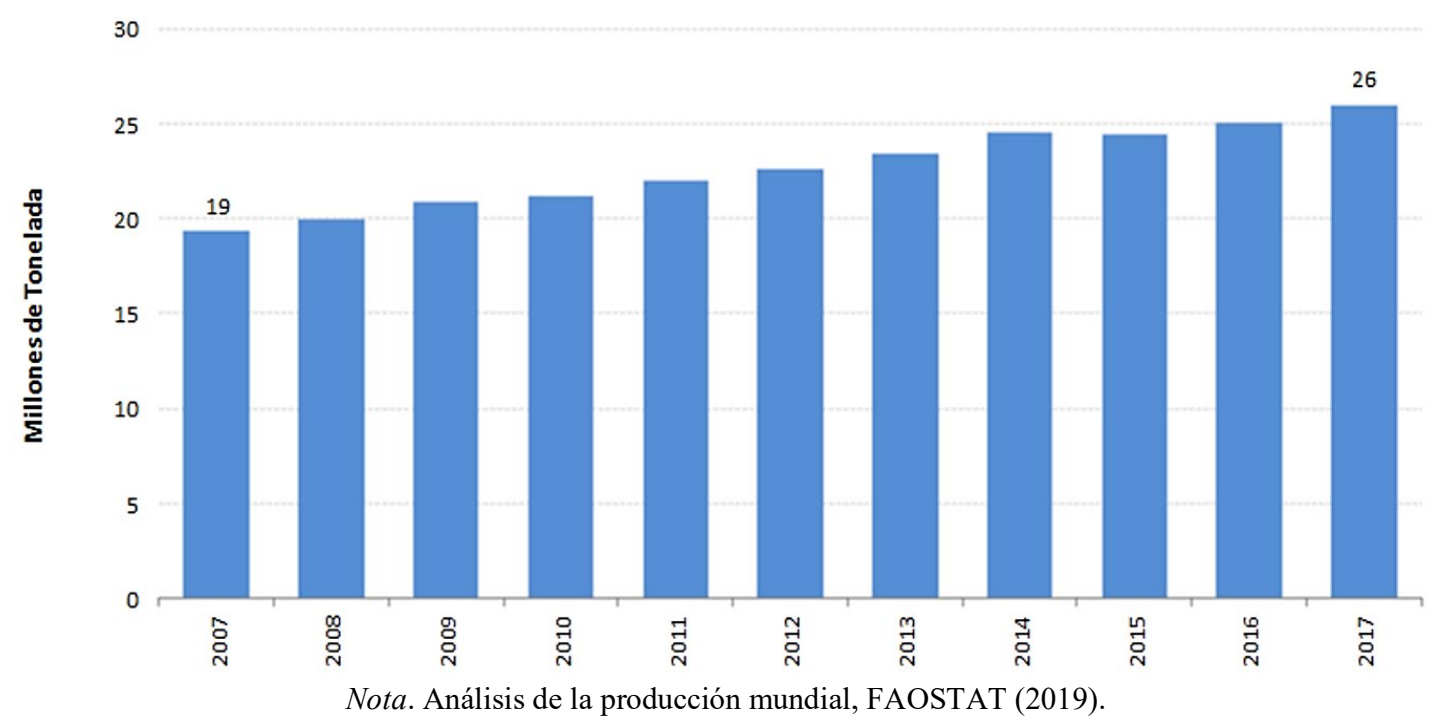

\section{Producción a nivel nacional del brócoli}

Debido al desarrollo del interés público y mundial, ha habido una expansión en el distrito establecido, llegando a un ordinario de más de 9.000 hectáreas. La base de las cosechas 
locales en 2018 mostró una expansión del 64\% en contraste con 2017, lo que se reflejó en el incremento de las mercancías locales (MAG, 2018).

\section{Figura 5}

Producción nacional de brócoli desde el año 2008 al 2018

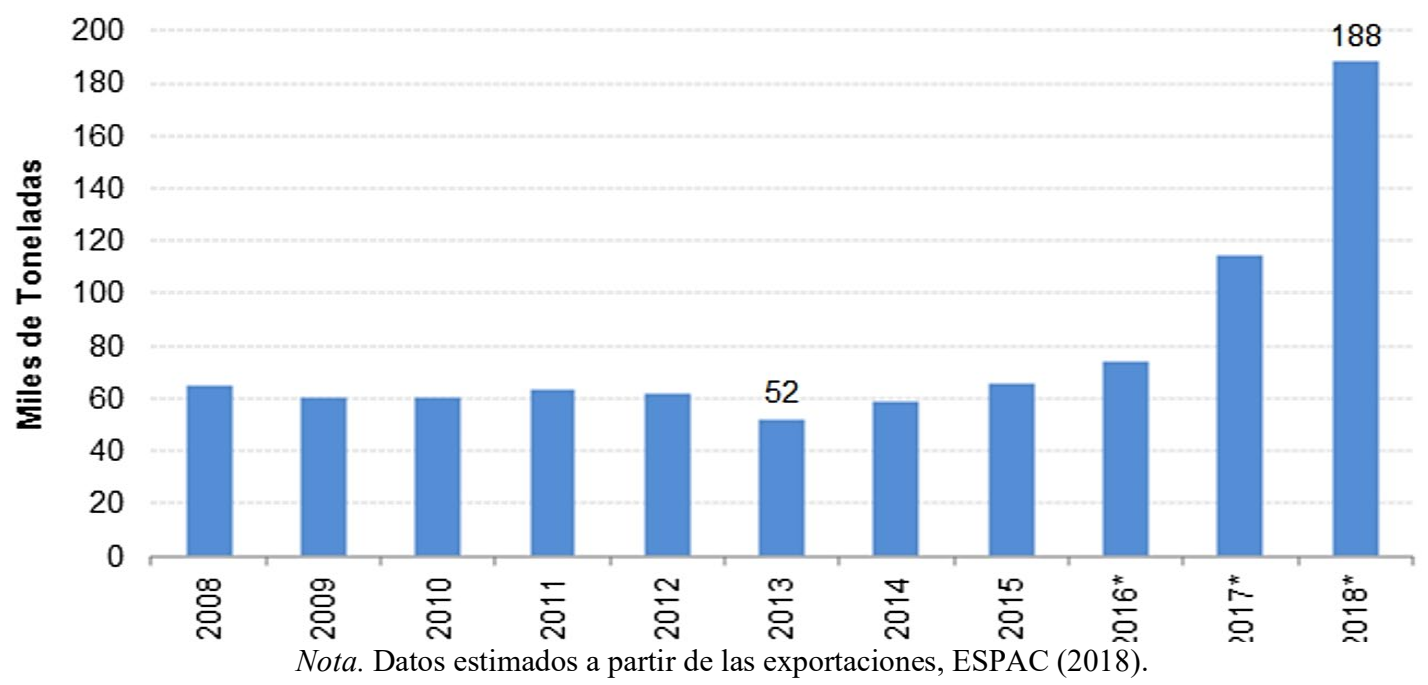

\section{Exportaciones a nivel internacional del brócoli}

La Unión Europea se encuentra entre los principales exportadores de brócoli, seguido de China, mientras que Ecuador también tiene una importante participación con sus exportaciones. Las exportaciones de broccoli a nivel internacional, durante el 2018, presentaron una leve disminución en relación al año 2017 (MAG, 2018).

\section{Figura 6}

Exportaciones mundiales de brócoli desde el año 2008 al 2018

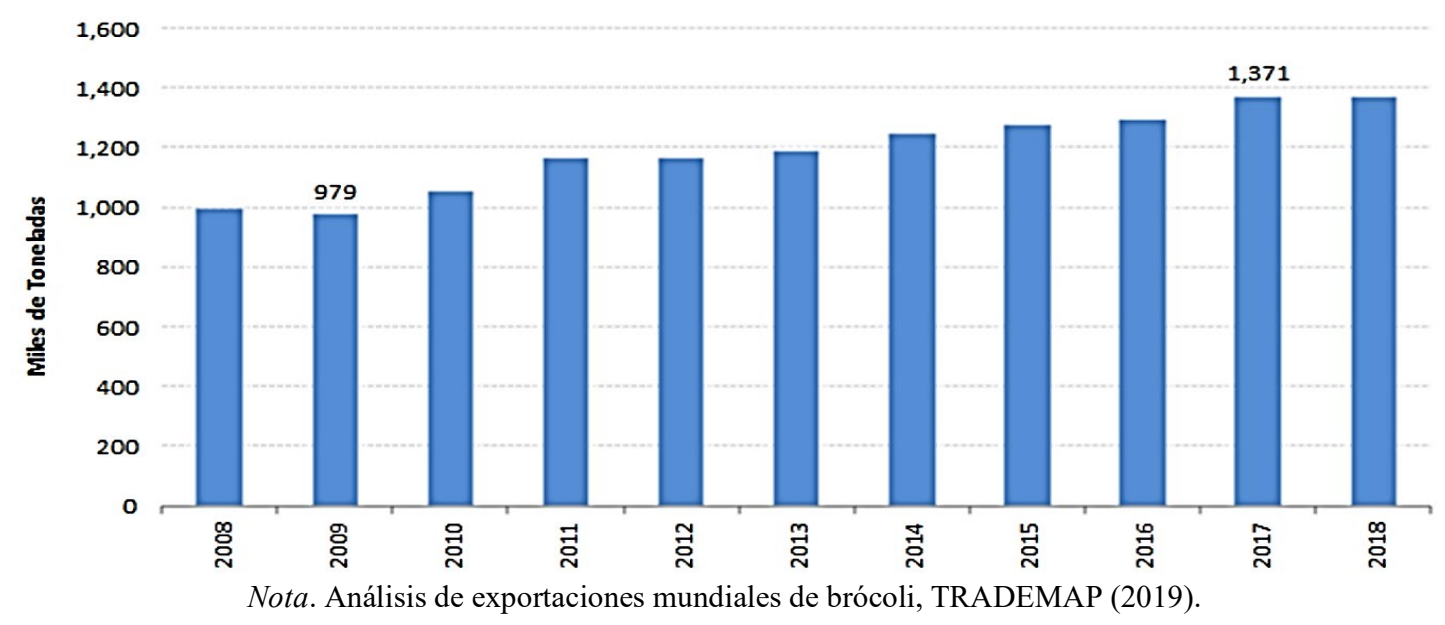

\section{Exportaciones a nivel nacional}

Las exportaciones ecuatorianas de esta hortaliza se han incrementado, ubicándose entre los principales productos de exportación no petroleros, debido fundamentalmente al cambio en los hábitos alimenticio. Ecuador registró exportaciones por 73634 toneladas, presentado un incremento en $12 \%$ con relación al año 2017 (MAG, 2018). 


\section{Figura 7}

Exportación nacional de brócoli fresco y congelado durante los años 2008-2018

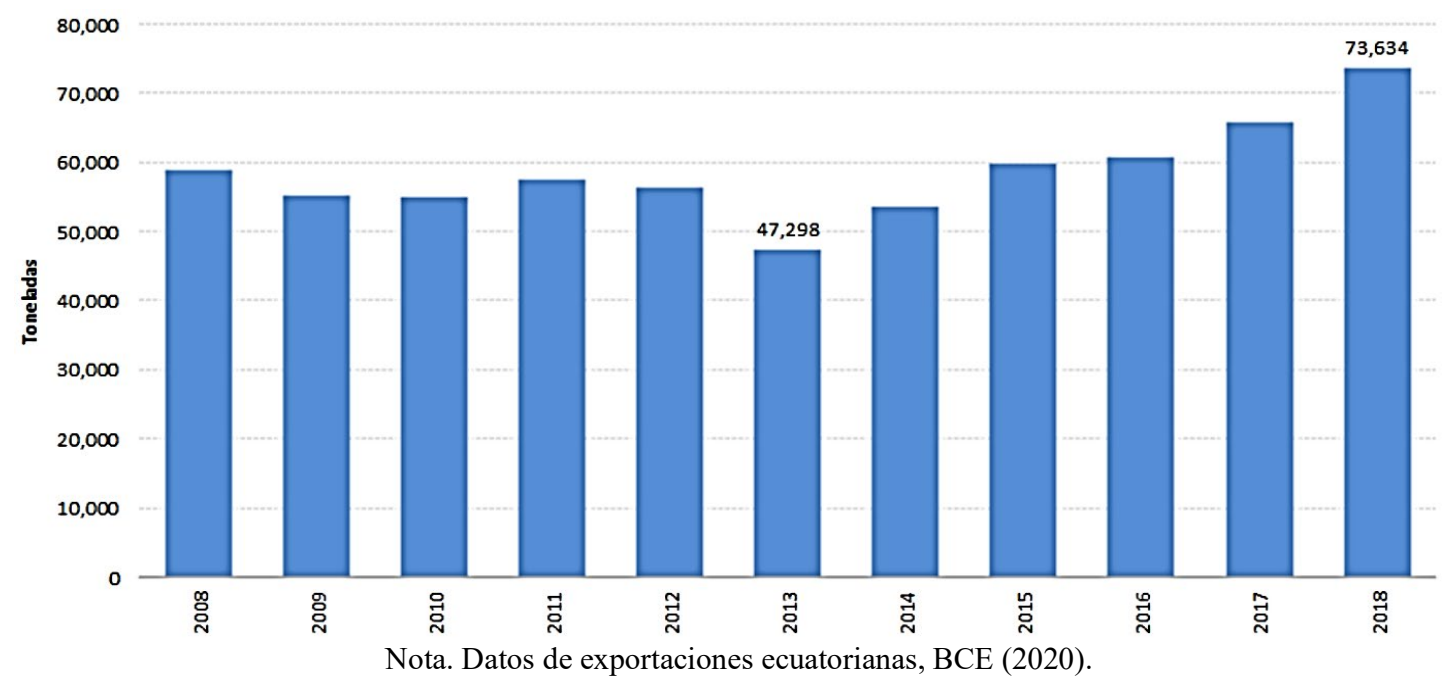

\section{Canales de comercialización}

Son las rutas por donde circulan los productos desde el centro de producción hasta llegar al consumidor final. Cuando es directo el canal de distribución la persona encargada de la fabricación vende directamente al consumidor final sin tener la necesidad de intermediarios Cuando es indirecto el canal de distribución el producto pasa por diferentes personas antes que lo obtenga el consumidor final. Los intermediarios encontrados entre el fabricante y el consumidor en un canal de distribución indirecto pueden tener incluido: Mayorista/ distribuidor, comerciante, minorista, consultor, representantes del fabricante y catálogos. Los canales de distribución son los que permiten que los esfuerzos de mercadeo sean una realidad y son uno de los soportes principales en la satisfacción del consumidor final (Sierra et al., 2015).

\section{Estructura del canal de comercialización}

De acuerdo con los criterios de clasificación, que son variados; el IICA Instituto Interamericano de Cooperación para la Agricultura, ha establecido un esquema que resume de alguna manera las inquietudes recolectadas en la comercialización agrícola (Tabla 2).

Los tres esquemas de comercialización propuestos, circuitos cortos, encadenamientos productivos y encadenamientos comerciales de productos diferenciados, exigen cierto nivel de organización, aunque se den casos de presencia de productores individuales, así como el cumplimiento de exigencias de calidad y formalización en la oferta $\mathrm{y}$, en cierta forma, corresponden a mercados "nicho", por lo que las opciones que representan no pueden considerarse como la solución para todos los productores agrícolas de pequeña y mediana escala y los agricultores familiares, y tampoco se pueden tomar como el único canal para comercializar toda la oferta (Flores, 2019).

A pesar del crecimiento y de la influencia que ese tipo de mercados van adquiriendo, los mercados tradicionales, con altos niveles de informalidad, siguen siendo los canales por los cuales se comercializa la mayor cantidad de los productos ofrecidos por los productores agrícolas de pequeña y mediana escala, incluidos los de la agricultura familiar. 
Tabla 2

Comercialización Agrícola según el IICA

\begin{tabular}{lllll}
\hline Estrategia Criterios & Tradicional & Circuitos cortos & $\begin{array}{c}\text { Encadenamientos } \\
\text { productivos }\end{array}$ & $\begin{array}{c}\text { Encadenamientos } \\
\text { comerciales }\end{array}$ \\
\hline $\begin{array}{l}\text { Organización de los } \\
\text { productores }\end{array}$ & No organizados & $\begin{array}{l}\text { Individuales y } \\
\text { organizados } \\
\text { informalmente }\end{array}$ & $\begin{array}{l}\text { Organizados informal } \\
\text { o formalmente }\end{array}$ & $\begin{array}{l}\text { Formalmente } \\
\text { organizados } \\
\text { principalmente }\end{array}$ \\
$\begin{array}{l}\text { Diferenciación del } \\
\text { producto }\end{array}$ & Genéricos & $\begin{array}{l}\text { Diferenciación sin } \\
\text { certificación }\end{array}$ & Genéricos & $\begin{array}{l}\text { Diferenciados con } \\
\text { certificación }\end{array}$ \\
$\begin{array}{l}\text { Distancia entre el } \\
\text { productor y el } \\
\text { consumidor final }\end{array}$ & Larga & Corta & Larga & Corta o larga \\
$\begin{array}{l}\text { Proximidad social } \\
\text { Distante }\end{array}$ & Sin acuerdos & Cercana & Distante & Cercana \\
$\begin{array}{l}\text { Tipo de acuerdo y } \\
\text { nivel de formalidad }\end{array}$ & previos & Nota Descripción de la comercialiación agrícola Flores (2019). & Con o sin acuerdos \\
\hline
\end{tabular}

\section{Beneficios de los estudios de mercado}

Los estudios de mercados ofrecen beneficios importantes a las empresas. Los más destacados son los siguientes:

1. Ofrecen una forma de medir la satisfacción del cliente.

2. Ayudan a diseñar estrategias de marketing más eficaces.

3. Permiten identificar oportunidades.

4. Permiten identificar el potencial del mercado.

5. Ayuda a minimizar el riesgo de pérdida o problemas potenciales.

6. Sirven como una herramienta de evaluación.

7. Permiten analizar a los competidores y crear planes estratégicos para vencer a los rivales.

\section{Importancia de los estudios de mercado}

Los estudios de mercados son importantes por muchas razones: permiten definir el tipo de clientes al que se desea llegar con el producto, la ubicación ideal para abrir el negocio, el precio más conveniente, que tipo de promoción hacerles a los productos, en fin, que permita ubicar e identificar con efectividad cual es y donde se encuentra el mercado potencial (Prieto, 2013).

La importancia del estudio de mercado se refiere a dos ideas relativas a las transacciones comerciales, se trata de un lugar físico especializado en las actividades de vender y comprar productos y en algunos casos servicios. En este lugar se instalan distintos tipos de vendedores para ofrecer diversos productos o servicios, en tanto que ahí concurren los compradores con el fin de adquirir dichos bienes o servicios.

También importante porque permite conocer las necesidades del cliente, lo que a su vez facilita ofrecer un producto o servicio que tenga la capacidad de satisfacer las necesidades y expectativas del mercado, de los clientes a los que nos dirigimos (Gerencie, 2020). 
No es prudente ofrecer un producto que no se necesita, o que tiene características diferentes a las que el público requiere, y eso se identifica con el estudio de mercado. Tampoco se debe ofrecer un producto a un precio distinto al que está dispuesto a pagar el cliente potencial.

\section{El análisis estratégico del mercado}

El estudio de mercado tiene que ver con el análisis de los clientes, el producto y los productos sustitutos de forma más analítica posible. Con ello podrán obtener lo que se llame FODA (Fortalezas, Oportunidades Debilidades y Amenazas), con el fin de aprovechar el potencial de mercado la empresa y prepararse para las debilidades de la empresa frente a la competencia y las amenazas que presenta el mercado (Prieto, 2013).

Una forma de investigar, analizar y mapear las particularidades presentes. Este análisis debe ser visto como elemento fundamental, ya que es un factor vital para tener éxito.

Con el objetivo de evaluar sus componentes presentes y futuros. A partir de él, es posible estructurar una estrategia con base científica, a fin de facilitar el alcance de una meta determinada, ya sea de crecimiento en el mercado, aumento de ventas, la disminución de costos con publicidad, etc.

En sí sería la única forma posible de tener conocimiento certero de los atributos positivos y negativos del ambiente interno. Contar con este tipo de datos es fundamental para entender efectivamente qué está funcionando y replicar el éxito en otras áreas del negocio.

Las definiciones establecidas deben girar en torno al propósito principal del negocio y es fundamental que las acciones seleccionadas, así como los objetivos y plazos, se basen en la investigación y consulta con expertos (Borges, 2020).

"El marketing es la actividad, conjunto de instituciones y procesos para crear, comunicar, entregar e intercambiar ofertas que tienen valor para los clientes, socios y la sociedad en general." - American Marketing Asociation (A.M.A.) (Marketing estratégico, 2018).

El marketing estratégico busca conocer las necesidades actuales y futuras de los clientes, localizar nuevos nichos de mercados, identificar segmentos de mercados potenciales, valorar el potencial e intereses de esos mercados orientar a la empresa en busca de esas oportunidades y diseñar un plan de actuación que consiga los objetivos buscados (Muñiz, 2008).

\section{Plan de marketing}

Son los planes operativos, llamados de esta forma porque consisten en la planificación concreta de objetivos, acciones, estrategias y asignaciones de recursos para el período de, por lo general, un año.

La estructura proporciona una visión clara del objetivo final y de lo que se quiere conseguir en el camino hacia la meta, a la vez informa con detalle de la situación y posicionamiento en los que nos encontramos, marcándonos las etapas que se han de cubrir para su consecución (Kotler y Armstrong, 2018).

El plan de marketing es esencial para el funcionamiento de cualquier empresa y la comercialización eficaz y rentable de cualquier producto o servicio, incluso dentro de la propia 
empresa. Intentar que un proyecto triunfe sin servirse de un plan de Marketing es como tratar de navegar en un mar de tempestuoso sin cartas marítimas ni destino claro, y bajo el ataque de los torpedos enemigos. La elaboración del plan de Marketing lleva tiempo, pero es tiempo bien invertido que, en definitiva, acaba por ahorrar tiempo (Sellers y Casado, 2010).

El plan de marketing proporciona una visión clara del objetivo final y de lo que se quiere conseguir en el camino hacia éste. A la vez, informa con detalle de las importantísimas etapas que se han de cubrir para llegar desde donde se está hasta donde se quiere ir. Tiene la ventaja añadida de que la recopilación y elaboración del plan de marketing permite calcular cuánto se va a tardar en cubrir cada etapa y los recursos en dinero, tiempo y esfuerzo necesarios para hacerlo. Sin el plan de marketing, ni si quiera sabe uno si ha alcanzado sus objetivos.

\section{Marketing mix}

El marketing mix es el conjunto de herramientas que debe combinar la dirección de marketing para conseguir los objetivos previstos, y se materializa en cuatro instrumentos: producto, precio, distribución y comunicación (Martínez et al., 2014).

El objetivo de las operaciones de marketing es encontrar una oferta de productos y servicios que incremente el nivel de satisfacción del comprador y genere utilidades para la empresa. Esta oferta está conformada, desde el punto de vista mercadotécnico, por un conjunto de variables controlables por la empresa.

Es preciso destacar que, debido a la abstracción de los conceptos, resulta difícil delimitar con absoluta claridad las fronteras entre el producto, el precio, la comunicación, la distribución y los servicios. De hecho, varias partes de la mixtura, como la marca, por ejemplo, están entre el límite del producto y la promoción; la fuerza de ventas y las nuevas tecnologías como el Internet y el telemarketing crean nuevas posibilidades de comunicación y distribución. Mayor imprecisión existe con relación al servicio; éste se da antes de la venta, con la venta y en la posterior venta.

De cualquier modo, estas decisiones y acciones, analizadas en forma desagregada en las siguientes páginas, conforman el marketing operativo y se constituyen en los medios con los cuales la empresa resuelve los problemas de los compradores, agregando valor y satisfacción (Peñaloza, 2005).

\section{El producto}

El producto es cualquier bien, servicio o idea que se ofrece al mercado y que representa el medio para satisfacer las necesidades o deseos del consumidor. Por ello, los beneficios que reportan los productos son más importantes que sus características (Martínez et al., 2014).

En los elementos básicos del marketing mix sus componentes son su calidad, sus características, su marca, tipo de empaquetado, diseño y servicios relacionados. Con el paso del tiempo se tendrá que manejar estas variables para desarrollar nuevos productos, para satisfacer las nuevas demandas del mercado o para adaptar los ya existentes, de forma que satisfagan la demanda por las modificaciones en las condiciones del mercado (Kotler y Armstrong, 2018).

\section{El precio}

$\mathrm{Al}$ establecer el precio, se debe tener en cuenta el valor percibido por el cliente y cuánto está dispuesto a pagar por el producto. El precio va a determinar a su vez la imagen que tendrá 
el cliente del producto, puesto que en muchas ocasiones un precio alto es sinónimo de calidad, mientras que un precio bajo refleja lo contrario (Martínez et al., 2014).

El precio se puede definir estrechamente como la cantidad de dinero que se cobra por un producto o servicio, o más ampliamente como la suma de los valores que los consumidores dan a cambio de los beneficios de tener y usar el producto o servicio (Kotler y Armstrong, 2018).

Según esto, el precio puede estudiarse desde dos perspectivas diferentes. La perspectiva del cliente, que lo utiliza como una referencia de valor, y la perspectiva de la empresa, para quien es una herramienta para generar recursos encaminados a recuperar la inversión realizada y obtener una ganancia.

Dejando de lado un poco las teorías económicas, el precio de venta en términos financieros, debe ser aquel valor suficiente para cubrir los costos variables y el Margen de contribución (Gerence, 2020).

\section{La plaza o distribución}

Al crear un canal de distribución: se requiere de un conjunto de organizaciones interdependiente que participan en el proceso de poner un producto o servicio a disposición de consumidor o usuario de negocios, para su uso o consumo (Kotler y Armstrong, 2018).

Los canales de distribución y la interrelación entre la fuerza de ventas y el mercado real, para enlazar a los agentes comerciales, desde el fabricante hasta el consumidor final. Es una de las áreas empresariales que se encuentran en mayor evolución. Es importante destacar que esta evolución no es homogénea en el mundo. Ciertamente, Europa sigue a pies juntillas las tendencias de estados Unidos. Por el contrario, el movimiento es muy dispar en México o Ecuador (Prieto, 2013).

La distribución hace referencia a la colocación del producto allá donde el consumo tenga lugar, es decir, se refiere a todas las decisiones que estén relacionadas con el traslado del producto desde el lugar de producción hasta el lugar de consumo (Martínez et al., 2014).

El canal de distribución representa cada una de las etapas que componen el recorrido del producto desde el fabricante hasta el consumidor final. En otras palabras, el canal de distribución está constituido por todo aquel conjunto de personas u organizaciones que facilitan la circulación del producto elaborado hasta llegar a manos del consumidor o usuario (Monferrer, 2013).

\section{La promoción}

Según la comunicación incluye actividades como la publicidad, la propaganda, la venta personal, la promoción de ventas, el marketing directo o las relaciones públicas. La dirección comercial debe estudiar cómo se van a combinar los diferentes instrumentos de comunicación para optimizar los recursos y conseguir los mejores resultados. El empleo de una u otra forma de comunicación depende de las características del producto, del mercado en el que se opere, de la competencia existente o del público objetivo, entre otras. Las decisiones relativas a la comunicación implican establecer:

1. La estrategia de la dirección de ventas, que incluye determinar el tamaño y composición del equipo de ventas, el reparto de tareas, el diseño de las zonas de venta, etc. 
2. El presupuesto destinado a comunicación.

3. Las herramientas de comunicación que se van a emplear (Martínez et al., 2014).

Este trabajo tiene como efecto comunicar acerca de la efectividad del producto dando a entender sus características, conveniencias y necesidades que satisface. Al mismo tiempo, la información debe actuar sobre los clientes actuales, recordando la calidad del producto y sus utilidades a fin de evitar que los habituales sean tentados por la competencia y adquieran otras marcas, para los clientes potenciales, persuadirlos para un estímulo positivo que los lleve a probarlo. Por lo tanto, podemos decir que la comunicación persigue tres objetos vitales: comunicar, convencer y reflexionar. (Monferrer, 2013).

\section{Exportaciones del Ecuador}

El brócoli gana protagonismo en la exportación no petrolera del país. El brócoli se ha ubicado en el octavo lugar de los principales productos de exportación no petroleros. Está por encima de los aceites vegetales, así como de los jugos y conservas de frutas.

En los primeros seis meses de 2020 las exportaciones de brócoli representaron para el país USD 83 millones, 36\% más que en el mismo período de 2019 cuando alcanzaron los USD 61 millones, según el Banco Central.

Ese incremento de ventas hizo también que el brócoli gane protagonismo en la canasta exportable no petrolera de Ecuador.

Entre enero y junio de 2020, este alimento se ubicó entre los 10 principales productos de exportación del país, según la Federación Ecuatoriana de Exportadores (FEDEXPOR).

El brócoli está en el octavo puesto del ranking, por encima de las exportaciones de aceites vegetales y de los jugos y conservas de frutas (Zeller, 2020).

\section{Figura 8}

Principales productos de exportación de enero-junio del 2020, en USD millones FOB

\begin{tabular}{|c|c|c|c|}
\hline Rubro & Valor FOB & Variación 2019/2020 & \\
\hline Banano y plátanoß̧ & 2.003 & $17,00 \%$ & \\
\hline Camarón(8) & 1.974 & $7,00 \%$ & \\
\hline Enlatados de pescado & 556 & $-6,00 \%$ & \\
\hline Flores naturales 8 & 464 & $-6,00 \%$ & \\
\hline Cacao y elaborados $\mathrm{E}$ & 369 & $26,00 \%$ & \\
\hline Madera y elaborados $Q$ & 238 & & $65,00 \%$ \\
\hline Atún y pescado@ & 171 & $0,03 \%$ & \\
\hline Brócoli $\odot$ & 83 & $36,00 \%$ & \\
\hline Aceites vegetales 0 & 80 & $-10,00 \%$ & \\
\hline Jugos y conservas de frutas 6 & 49 & $7,00 \%$ & \\
\hline
\end{tabular}

Nota. Datos de los principales productos de exportación del Ecuador, FEDEXPOR (2020).

\section{Destinos del brócoli}

"El 83\% de la oferta exportable del país la concentran en 10 principales productos de exportación, cuyos consumidores más importantes se encuentran entre Estados Unidos, y en los países de Asia y Europa”, explica Fedexpor. 
En el caso del brócoli ecuatoriano su principal destino es Estados Unidos. En el caso de Provefrut, el $50 \%$ de sus exportaciones se dirige a ese país, mientras que el otro $50 \%$ se destina a varios países de la Unión Europea y Japón.

En Estados Unidos el principal competidor del brócoli ecuatoriano es el de México y los países de Centroamérica. En el caso europeo son los mismos países de ese bloque regional.

Además, el competidor mundial es el brócoli que proviene de China, aunque "su calidad no se compara", asegura (Zeller, 2020).

\section{Estadísticas del Brócoli en el año 2019}

Según el BCE, nos da un enfoque a las estadísticas del 2019 en la exportación del brócoli, el valor fue de USD128'205 021.

\section{Figura 9}

Exportación de brócoli de enero-diciembre 2019

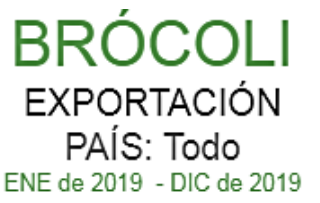

VALOR: 128.205.021 USD

PARTICIPACIÓN AGROPECUARIA: $1,90 \%$

PESO: $80.283 \mathrm{t}$

POR PRODUCTO

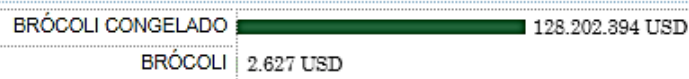

Nota. Datos de exportación de brócoli, BCE (2019).

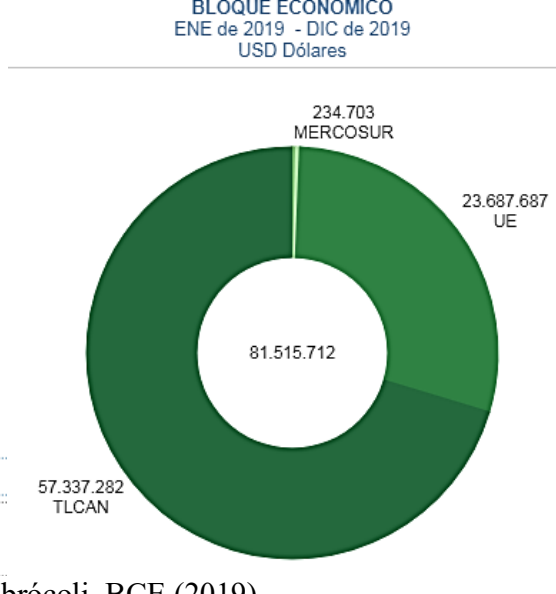

BLOQUE ECONÓMICO 2019

Figura 10

Principales destinos de exportación de enero-diciembre del 2019

\begin{tabular}{|c|c|c|c|}
\hline \multicolumn{4}{|c|}{$\begin{array}{l}\text { PRINCIPALES DESTINOS DE EXPORTACION } \\
\text { ENE de } 2019 \text { - DIC de } 2019\end{array}$} \\
\hline No, & País & Valor (USD) & Peso (t) \\
\hline 1 & JAPÓN & 50.110 .014 USD & 27.251 \\
\hline 2 & ESTADOS UNIDOS & 39.620 .887 USD & 24.266 \\
\hline 3 & ALEMANIA & 10.229 .553 USD & 7.583 \\
\hline 4 & CANADÁ & 9.808 .848 USD & 7.022 \\
\hline 5 & PAISES BAJOS (HOLANDA) & 4.169 .979 USD & 3.183 \\
\hline 6 & REINO UNIDO & 3.763 .035 USD & 3.032 \\
\hline 7 & BÉLGICA & 3.325 .582 USD & 2.395 \\
\hline 8 & RUSIA & 2.176 .527 USD & 2.014 \\
\hline 9 & TAIWÁN & 1.110 .660 USD & 567 \\
\hline 10 & FINLANDIA & 860.258 USD & 661 \\
\hline 11 & SUECIA & 812.107 USD & 626 \\
\hline 12 & MÉXICO & 491.296 USD & 408 \\
\hline 13 & DINAMARCA & 452.389 USD & 283 \\
\hline 14 & ISRAEL & 312.589 USD & 168 \\
\hline 15 & NORUEGA & 256.033 USD & 202 \\
\hline 16 & EMIRATOS ÁRABES UNIDOS & 251.065 USD & 199 \\
\hline 17 & ARGENTINA & 156.615 USD & 177 \\
\hline 18 & NUEVA ZELANDIA & 102.251 USD & 81 \\
\hline 19 & URUGUAY & 78.088 USD & 70 \\
\hline 20 & POLONIA & 55_124 USD & 42 \\
\hline
\end{tabular}




\section{Estadísticas del Brócoli en el año 2020}

Según el BCE, da un enfoque a las estadísticas del 2020 en la exportación del brócoli, el valor fue de USD116,289,146.

\section{Figura 11}

Exportación de brócoli de enero-septiembre del 2020

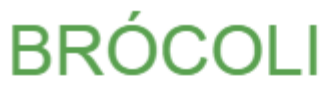

EXPORTACIÓN

PAÍS: Todo

ENE de 2020 - SEP de 2020

Último dato disponible SEP 2020

VALOR: 116.289 .146 USD

PARTICIPACIÓN AGROPECUARIA: 2,10\%

PESO: $68.000 \mathrm{t}$

POR PRODUCTO BRÓCOLI CONGELADO

Figura 12

Principales destinos de exportación de enero-septiembre del 2020

\begin{tabular}{|c|c|c|c|c|}
\hline \multicolumn{5}{|c|}{$\begin{array}{l}\text { PRINCIPALES DESTINOS DE EXPORTACION } \\
\text { ENE de } 2020 \text { - SEP de } 2020\end{array}$} \\
\hline No, & País & $\Sigma$ & Valor (USD) & Peso (t) \\
\hline 1 & ESTADOS UNIDOS & & 43.028 .973 USD & 23.631 \\
\hline 2 & JAPÓN & & 38.718 .001 USD & 20.895 \\
\hline 3 & ALEMANIA & & 9.805 .001 USD & 6.666 \\
\hline 4 & CANADÁ & & 9.119 .806 USD & 5.483 \\
\hline 5 & PAISES BANOS (HOLANDA) & & 4.233 .040 USD & 3.048 \\
\hline 6 & REINO UNIDO & & 3.297 .313 USD & 2.460 \\
\hline 7 & BÉLGICA & & 2.674 .814 USD & 1.816 \\
\hline 8 & RUSIA & & 1.304 .313 USD & 1.230 \\
\hline 9 & TAIWÁN & & 1.067 .564 USD & 579 \\
\hline 10 & FINLANDIA & & 717.317 USD & 562 \\
\hline 11 & SUECIA & & 569.202 USD & 359 \\
\hline 12 & MÉXICO & & 417.779 USD & 186 \\
\hline 13 & NORUEGA & & 378.304 USD & 314 \\
\hline 14 & ISRAEL & & 237.764 USD & 137 \\
\hline 15 & ARGENTINA & & 220.911 USD & 241 \\
\hline 16 & EMIRATOS ÁRABES UNIDOS & & 112.946 USD & 90 \\
\hline 17 & DINAMARCA & & 94.307 USD & 63 \\
\hline 18 & URUGUAY & & 69.522 USD & 39 \\
\hline 19 & COREA (SUR), REPÚBLICA DE & & 66.511 USD & 64 \\
\hline 20 & POLONIA & & 54.288.USD & 42 \\
\hline
\end{tabular}




\section{Conclusiones}

El consumo de brócoli se ha incrementado en los últimos años, debido principalmente al cambio de los hábitos alimenticio, lo que ha generado un aumento en la demanda de esta hortaliza en los mercados nacionales e internacionales.

El brócoli ecuatoriano es muy apetecido en los mercados internacionales, por su calidad, los principales destinos son Japón, Estados Unidos, la Unión Europea, Canadá entre otros.

Los canales de comercialización de esta hortaliza están conformados por los pequeños y medianos productores, los intermediarios que son las empresas procesadoras que son quienes exportan el producto hacia los diferentes destinos.

Las principales provincias productoras de esta hortaliza son Cotopaxi, Chimborazo, Tungurahua, Imbabura, Pichincha, Azuay, Cañar y Loja, con una superficie total que sobrepasa las 9000 hectáreas.

Por último, es una gran fuente de ingreso de divisa para el país, es dinamizadora de la economía ya que genera empleo en el sector agropecuario en la región interandina del país.

\section{Reconocimientos}

Los autores agradecen a las autoridades de la Universidad Agraria del Ecuador, por su gran apoyo para llevar adelante el desarrollo y culminación de este trabajo de investigación.

\section{Referencias}

Alvarado Alvarado, A. F., \& Huiracocha Uyuguari, M. E. (2014). Impacto de los costos de expotacion de brocoli por la renuncia de ecuador a la ley de promocion comercial andina y erradicacion de drogas con los Estados Unidos de America. UDC, 219.

Álvarez, L., \& Álvarez, A. (2009). Estilos de vida y Alimentaciòn. Gazeta de Antropologia, 1-14. Obtenido de https://www.ugr.es/ pwlac/G25_27Luis_Alvarez-Amaia_Alvarez.pdf

BCE. (2019). SIPA. Obtenido de http://sipa.agricultura.gob.ec/index.php/comercio-exterior

Borges, C. (08 de Enero de 2020). El análisis estratégico es fundamental para garantizar una buena orientación para la toma de decisiones y el establecimiento de metas en las empresas. (Marketing B2B na Rock Content, Intérprete)

Calvopiña Rodríguez, D. L. (Abril de 2015). Repositorio PUCE. Obtenido de Pontificia Universidad Católica del Ecuador: http://repositorio.puce.edu.ec/bitstream/handle/22000/8373/DISERTACI\%C3\%93N\%20Dayana\%20Li zbeth\%20Calvopi\%C3\%B1a\%20Rodr\%C3\%ADguez.pdf?sequence=1\&isAllowed=y

Cesaveg, C. E. (2001). Contingencia de manejo fitosanitario de crucíferas.Brócoli, coliflor y col. México.

Economia, S. d. (2011). Estudio de Mercado - La oferta. Guias Empresariales. Obtenido de http://www.contactopyme.gob.mx/cpyme/guiasempresariales/guias.asp?s=10\&g=2\&sg=13

Enriquez, C. (2017). El brócoli mantiene una alta demanda externa. Revista Lideres.

FAO. (2013). Obtenido de http://www.fao.org/3/a-i3434s.pdf

Flores Gavilanes, A. (2019). Los canales de comercialización y el desarrollo económico local de los productores agropecuarios de la parroquia Benitez, del cantón San Pedro de Pelileo. Ambato Ecuador. 
García, E. (2016). Formas de aplicación y dosis de ranman (ciazofamid) para controlar Plasmodiophora brassicae en Brassica oleracea var. italica cv. „Legacy“. Arequipa- Perú.

Gerence . (23 de Octubre de 2020). Obtenido de https://www.gerencie.com/precio.html

Gerencie. (19 de Mayo de 2020). Obtenido de https://www.gerencie.com/la-importancia-de-hacer-un-estudiode-mercado.html

Giron, N., \& Plazas, K. (2019). Los hábitos alimenticios en la familia y su incidencia en el desarrollo integral de los niños y niñas del preescolar del Centro Educativo Rural El Convento del Municipio de Trinidad Casanare. TESIS. YOPAL.

Gomez, R. (06 de Marzo de 2016). Empresas y productores de brócoli, generan alrededor de 19 mil plazas de trabajo, tanto directas como indirectas en Cotopaxi. Cotopaxi, Ecuador.

Kotler, P., \& Armstrong, G. (2018). Principios de Marketing. Madrid - España: Pearson Educación.

Larrea Serrano, I. H. (26 de Febrero de 2016). El Universo. Obtenido de https://www.eluniverso.com/opinion/2016/02/29/nota/5435295/agricultura-ecuador

Lìderes, R. (2017). El brócoli tiene mercado que aumenta en Europa. Revista Líderes. Obtenido de https://www.revistalideres.ec/lideres/brocoli-mercado-europa-produccion-economia.html

Luna, E. (2017). Evaluación de dos variedades de brócoli (Brassica oleracea) bajo tres densidades de plantación en ambiente atemperado en la estación experimental de Cota-Cota. La Paz: Universidad Mayor de San Andrés. Obtenido de https://repositorio.umsa.bo/xmlui/bitstream/handle/123456789/12871/T2379.pdf? sequence $=1 \&$ isAllowed $=\mathrm{y}$

Marketing estratégico. (08 de Marzo de 2018). Obtenido de Academia de consultores: https://academiadeconsultores.com/marketing-estrategico-y-funciones/

Martínez, A., Ruiz, C., \& Escrivá, J. (2014). Marketing en la actividad comercial. Madrid - España: McGrawHill.

Mercola. (08 de Enero de 2017). Obtenido de https://alimentossaludables.mercola.com/brocoli.html

Ministerio de Agricultura y Ganaderia. (2018). SIPA. Obtenido de http://sipa.agricultura.gob.ec/index.php/legumbres-hortalizas/brocoli

Monferrer, D. (2013). Sapientia. Obtenido de Fundamentos de Marketing.

Muñiz, R. (2008). Marketing en el siglo XXI. Madrid - España: CEF.

Orozco, M. (11 de Octubre de 2019). El comercio. Obtenido de https://www.elcomercio.com/actualidad/negocios-sector-brocoli-declaracion-emergencia.html.

Peñaloza, M. (2005). El Mix de Marketing: Una herramienta para servir al cliente. Actualidad Contable Faces, 74. Obtenido de https://www.redalyc.org/pdf/257/25701007.pdf

Portilla España, D. C. (2013). “La Demanda de brócoli en el mercado de Tokio - Japón y su Comercialización desde la Provincia del Carchi”. Tulcán - Ecuador .

Prieto, J. (2013). Investigación de mercados. Bogotá- Colombia: ECO.

ProEcuador. (7 de Febrero de 2014). Obtenido de http://www.proecuador.gob.ec/2014/02/07/brocoli-segundoproducto-notradicional-mas-importante-de-la-sierra-ecuatoriana/

Rendón, A. (2013). Brócoli, Panorama Internacional. Ministerio de Agricultura Ganadería Acuacultura y Pesca-MAGAP. 
Rivera, J., \& De Garcillán, M. (2012). Dirección de Marketing. Fundamentos y aplicaciones. España: ESIC.

Rojas, M. (2015). Evaluación de proyectos para ingenieros. Bogotá - Colombia: ECOE.

Rubio, B. (2016). La fase de transición mundial y el dominio agroalimentario de Estados Unidos: una visión histórico-estructural. Revista Latinoamericana de Estados Rurales 2 (1), 137 - 158.

Sellers, R., \& Casado, A. (2010). Introducción al Marketing. San Vicente - España: Club Universitario.

Zamora, E. (Enero de 2016). Universidad de Sonora. Obtenido de http://dagus.uson.mx/Zamora/BROCOLIDAG-HORT-010.pdf

Zeller, A. (2020). El brócoli gana protagonismo en la exportación no petrolera del país. (G. Coba, Entrevistador) Obtenido de https://www.primicias.ec/noticias/economia/brocoli-espacio-canasta-exportaciones/ 